\title{
G A とS A を併用したニューラルネットワークの設計と硬貨識別への応用
}

\author{
満 倉 靖 恵*·福 見 稔*·赤 松 則 男*
}

\author{
Design and Evaluation of Neural Networks for Coin Recognition by Using GA and SA ${ }^{\dagger}$
}

Yasue MitsukuRA*, Minoru FukUmi* and Norio AkAmatsu*

\begin{abstract}
In this paper, we propose a method to design of a neural network(NN) by using a genetic algorithm(GA) and simulated annealing(SA). And also, in order to demonstrate the effectiveness of the proposed scheme, we apply the proposed scheme to a coin recognition example.

In general, as a problem becomes complex and large-scale, the number of operations increase and hardware implementation to real systems (coin recognition machines) using NNs becomes difficult. Therefore, we propose the method which makes a small-sized NN system to achieve a cost reduction and to simplify hardware implementation to the real machines.

The coin images used in this paper were taken by a relatively cheap scanner (scanning $12 \mathrm{~mm}$ in width). Then they are not complete, but a part of the coin image could be used in computer simulations. This is the reason why the width of coin images is limited. If the conventional scheme was used for this image, it would have low recognition accuracy. Therefore, in order to obtain high recognition accuracy, we propose a new scheme.

Input signals, which are Fourier spectra, are learned by a three-layered NN. The inputs to NN are selected by using GA with SA to make a small-sized NN. Simulation results show that the proposed scheme is effective to find a small number of input signals for coin recognition.
\end{abstract}

Key Words: neural network, genetic algorithm, simulated annealing, coin recognition

\section{1. 緒言}

近年, 人間の脳における情報処理のメカニズムが一部明ら かにされ，これらをニューラルネットワークとして人工的に 実現する試みがなされている1)。さらに, ニューラルネット ワーク $(\mathrm{NN})$ はパターン認識, システム同定, さらには学 習・適応制御など，幅広い分野に適用されている。とくに， パターン認識の分野においてはNNを用いた硬貨識別ならび に，応用例などが数多く提案されている2) 7). しかしなが ら，一般にNNは，問題が大規模・複雑になるにつれ演算量 が多くなり，実機（たとえば，コイン識別機）などへのハー ドウェア化が難しくなっている。そこで，本論文では，実機 へのハードウェア化をより簡単にするために，N Nシステム を小さくする方法を提案し，硬貨識別に適用する.

硬貨識別問題においては，これまでにも，N Nシステムを 小さくする方法としていくつかの方法が提案されているが 4) 6), これらは, 硬貨の画像が完全なものを学習・認識に 用いるので，画像をスキャナで取り込む際に，すでに多大な

†第 8 回 SICE 中国支部学術講演会 (1999.11)

* 徳島大学工学部 徳島市南常三島町 2-1

* Faculty of Engineering, University of Tokushima, 2-1 Minami-Josanjima Tokushima, Tokushima

(Received December 6, 1999)

(Revised September 4, 2000)
コストがかかっている．実機へのハードウェア化を考える上 で, 最も重要な点は望ましい認識システムであるとは限らな かった。

そこで, 本論文では, これら $1 \sim 3$ の項目に対して, 比較 的安価なスキャナ（スキャン幅約 $12 \mathrm{~mm}$ ) で取り込んだ硬貨 の画像を用いることで, 低コストのシステムを実現する。こ のスキャナから取り込まれれる硬貨の画像の範囲は小さいた め, 完全な画像を使用している従来技術文献 3) 〜 5) をその まま適用すると，認識率が低下したり，認識部分のサイズが 大きくなる問題点があった。これらの点に着目し，本論文で は, 比較的安価なスキャナにおいても, 高価 (高性能) なス キャナで読み込んだ画像を用いた時と同等の認識率を得るこ とを目的としている．また，計算コストの削減も考慮し， N Nシステムを小さくすることを目的としている.

一方，生物の遺伝や進化のメカニズムを模擬した遺伝的 アルゴリズム (Genetic Algorithm;GA) ${ }^{8) \sim 11)}$ や, 熱平衡に ある物理系の温度を徐々に低下させてゆくと系は最終的に は結晶状態などエネルギーが最小の状態に落ち着く, とい う物理現象にヒントを得たシミュレーテッド・アニーリング (Simulated Annealing: S A) 法 ${ }^{9}$ が注目され, 工学の広い 分野に応用されている。これらは, 最適化手法などに用いら れているが， GAのみあるいは， S Aのみで用いるとそれぞ れのメリット・デメリットがあり，必ずしも望ましい值を得 
られない場合も少なくない。そこで本論文では，この G A と S A 法を併用することで, ‘大域的な局所探索”を行い, ‘短 時間により望ましい解, を得ることを目標とし,この G A と S A 法を併用したシステムにより N Nへの望ましい（必要最 小限の）入力属性を探索することで，より小さな N Nシステ ムを設計する。これまでにも GAとS Aを併用して最適化問 題を解く方法が提案されているが12), これらの方法は $\mathrm{GA}$ A 突然変異の代わりにS Aを用いる方法であり，探索して得ら れた特定の解に対して S A を行なう方法であった。本論文で は染色体の長さを分割し, これらに対して個々にSAを行っ ていることから, 分解能が小さくなり, 探索性能がよくなる 点で，これまでに提案された手法とは異なっていると考えら れる。

以下では, まず, 硬貨識別問題における演算量削減化の方 法について述べ, 次に, 具体的な演算量削減化と G A と S A 法を用いた N Nの設計法について述べる. 最後に, 数值シ ミュレーションを通して本手法の有効性について検証する。

\section{2. 硬貨認識問題}

\section{1 使用した硬貨の特徵}

本論文で考察する硬貨認識システムが行うべきタスクは, 未完全な硬貨のデータを用いて正しく認識させることである. この研究の背景として, 近年, 韓国の 500 ウォン硬貨が 500 円硬貨として使用される犯罪が多発している13). 関西では 1 999 年 9 月の 1 ケ間に一万枚の 500 ウォン硬貨が 500 円 硬貨として使われる事件も起こっている。 これらの硬貨は, 大きさ, 重さ, 色彩, パターンなどが類似しているため, そ れらの識別が以前から問題になっていた。 そこで, 本論文で は, 実際の硬貨識別機へのハードウェア化を考慮した上で, GAとSAを併用したN Nを用いて 500 ウォン硬貨（裏・表） と 500 円硬貨 (裏・表) を正確に認識させる方法を提案する.

まず，システムへの入力は Fig.1 に示すような， 500 円硬 貨と 500 ウォン硬貨の画像の一部である. 用いた画像は 256 階調 B MPファイルの画像であり, サイズは横が 49 ピクセ ル, 縦が 106 ピクセルのものである. また, これらの画像は すべて異なる硬貨を用いたものである.

硬貨識別までの簡単な手順は以下の通りである.

1.硬貨の画像デー夕をスキャナで取り边む.

2.データの形を極座標に変換する.

3.2 次元フーリエ変換を行う.
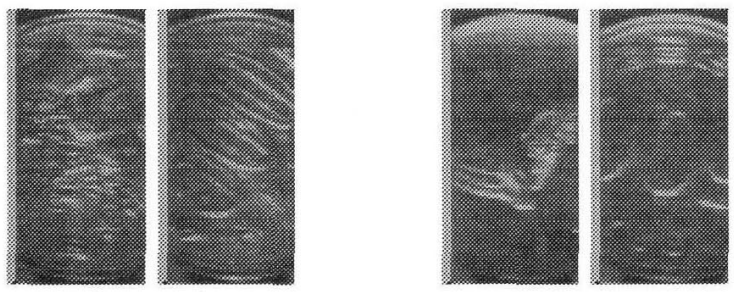

Fig. 1 A 500 yen coin and a 500 won coin

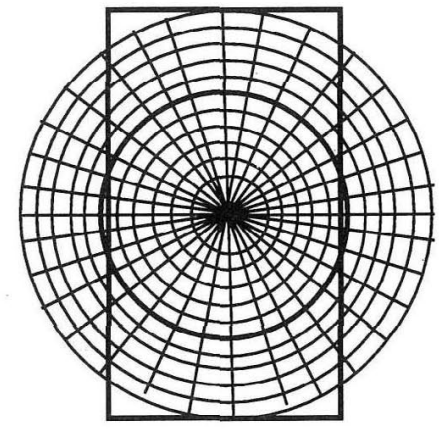

Fig. 2 The formation of the coin

\section{N Nで学習する.}

$\mathrm{NN}$ 学習は, フーリ工変換後の振幅スペクトルを N Nの入 力として学習させるが, このとき, 振幅スペクトルをすべて 学習に使うのではなく，GAとSAによる前処理を行うこと で，必要最低限の振幅スペクトルを探索する。これにより， 計算量を削減させる。

また，これまでに提案されている方法では，実際に銀行な どで使用されている硬貨識別器のイメージスキャナで読み込 まれた硬貨の画像を使用して認識していたが3) 6)，本手法で は，身近にある安価なスキャナで読み込んだ画像を使用する。 この場合, Fig.1からも分かるように, 画像全体をスキャン するのではなく，硬貨の一部だを取り込む(スキャン幅に 制限があるため）が，コストを大幅に削減することが可能で ある。

\section{2 演算量の削減化}

Fig.2において，スキャナにより取り込んだ硬貨の画像を 四角形で表される部分とすると，一番外側の円が実際の 500 円，または 500 ウォン硬貨を表わす。ここで，太線で描かれ た円を $16 \times 32$ 分割の直交座標に変換する。この画像に対 して二次元離散フーリエ変換を実行することで, 回転に不変 な信号にする，そして，このフーリエ変換後の振幅スペクト ルを NNへの入力とする。このとき，画像のない部分は 0 を 入れる。

しかしながら, 硬貨の画像を半径方向 16 と円周方向 32 に 分割した場合, $\mathrm{NN}$ への入力信号は $16 \times 32(=512)$ となり, 実機へのハードウェア化に大きく影響を与える，また，画像 の分割数を小さくすれば, 入力信号の数は削減できるが, こ の場合, 認識率が悪くなってしまうため, $16 \times 32$ 点以下の F F Tを用いることはできない，ところで，たとえば $16 \times$ 32 点の F F Tを用いた場合, 512 個すべての振幅スペクトル が必要であるとは限らない. 従って, 本論文では, フーリエ 変換後の振幅スペクトルを，GAとSAを併用することで, 必要最低限の入力のみに削減し, 得られた入力により N Nを 学習させることで，演算量を削減させる。 


\section{GAとSAを併用したNNの設計}

\subsection{GAとSAの併用}

G A は生物の遺伝や進化のメカニズムを工学的に模擬した アルゴリズムで, 探索・学習, および最適化の一手法として 工学の広い分野に応用されている. しかしながら, 従来から 用いられている単純遺伝的アルゴリズム（単純 G A ）では， 問題が大規模・複雑になると, しばしば局所的な最適解（か なりよい解ではあるが）に落ち込んで, 真の最適解が得られ ない場合もある。一方, 組み合せ最適化問題の一つの解法と して, 統計物理学における熱平衡状態の確率分布の性質を利 用した, シミュレーテッド・アニーリング法が提案され，目 的関数のローカル・ミニマムからの脱出が可能であるとされ， 多くの分野で応用が試みられている。しかしながら，SAに は，最初にどのくらいの探索空間から始めるべきかという問 題がある。このように, GAも S A も単独で使うと, メリッ トもあるが，デメリットの方も少なくない，そこで，本論文 では GAと SAを併用し，まず，GAにより，大域的に解の 集団を探索した後, S Aを用いて探索した集団における局所 最適解の探索をし，同時に局所解からの脱出をはかることで， 広範囲においてより最適な解を求める事ができる。このよう な G A-S A 法を用いてNNを設計する.

\section{$3.2 N$ Nの入力の決定}

ここでは, 前章までに述べてきた $\mathrm{G} A$ と S A を併用した N $\mathrm{N}$ の入力の決定方法の手順を以下に示す．GAにおける染色 体はフーリエ変換後の振幅スペクトルすべてに 0,1 を対応 づける.つまり, $16 \times 32(=512)$ のフーリエ変換を行なった 場合, 染色体の長さは 512 となる。このとき，0は学振幅 スペクトルを『使用しない』に相当し，逆に 1 は『使用する』 を意味している。

【Step1】初期設定：振幅スペクトルすべてを $\mathrm{G}$ A の遺伝子を 1 (使用する), 0 (使用しな い)に対応づける(初期集団 $\left\{I^{0}\right\}$ のランダム発 生, 各種パラメー夕の設定, $i=1)$.

【Step2】適応度関数 $\{f(i, j)\}$ の計算. ここで, $f(i, j)$ は第 $i$ 世代, 第 $j$ 番目の個体の適応 度関数を表わしている.

【Step3】選択・交叉・突然变異による次世代の集団 $\left\{I^{i}\right\}$ の発生.

【Step4】rの確率で S A 法を実行する.

【Step5】世代数 $i$ を $i+1$ として【step2】へ.

\section{3 適応度関数}

実機に適用することを考えると， N N システムは小さく， かつ, 高い認識率を得られなければならない. そこで, 本論 文では適応度関数として次式を用いる.

$$
f(i)=A / \text { 個体数 }+B / \text { 個体数 }
$$

ここで，A は認識率を高い順に番号を付け，B は染色体の 1 の数が少ない順に番号を付ける，ただし，一般的な G Aは適 応度を高くする方向に進化させるが，ここでは $f(i)$ の值が小 さいものが適応度が高いものとする．このような適応度関数 を用いることで, 認識率が高く, しかも， NNの入力の数が 少ないシステムを得ることが可能である。

\section{4. 計算機シミュレーション}

本手法の有効性を検証するために, 計算機シミュレーショ ンを行った，GAの各種パラメータを以下に示す。

個体数 : 40

世代数 : 40

交叉：2 点交叉

突然変異の確率 : $p_{m}=0.02$

このとき, 次世代へ残す個体の選択，交叉する個体は適応度 順位方式（ランキング方式）に従う。また，S Aを行う確率 $r$ を $20 \%$ とし，各種パラメータを以下に示す.

温度勾配 $\alpha: 0.90$

初期温度 $T_{0}: 1000$

終了条件 : $\alpha<0.1$.

S Aにおいては, 10 個体を適応度の高いものから順に選択す る。このとき，染色体は 512 の長さを持っているが，これら を 32 分割し，分割した 16 ビットずつを 10 進数に変換した 值のスカラー值の個々に対して SAをそれぞれ実行する。こ れらにより, 分解能が小さくなり, 探索性能がよくなると考 えられる。次に, NNに拈ける各種パラメー夕は以下の通り である。

層数 : 3

入力層のユニット数 : 最大で 512

中間層のユニット数 $: 20^{\text {(注 } 1)}$

出力層のユニット数 : 4 (2枚の硬貨の裏·表)

学習に用いた硬貨の画像：120 枚

認識に用いた硬貨の画像：320 枚(学習に用いた画像を 含む)

本論文でのシミュレーション結果は 10 回同様のシミュレー ションを行なった上で, 一番結果の良い例を示す．このとき， G A と S A を併用してNNの入力デー夕を探索した場合の有 効性を検証すために，G Aのみを用いて入力デー夕の探索を した場合との比較を Fig.3に示す：ここで，Fig.3の横軸は 世代数で縦軸はその世代における適応度の一番高い個体の持 つ適応度の値である．Fig.3において，GAによるNNの入 力探索の収束状況を確認するために世代数を増やし, 実験し

（注 1）中間層のユニット数は，B P 法のみの学習において，ユ ニット数を $5,10,15,20,25,30$ と変化させ, 10 シミュレーション を行ない, 10 回の平均認識率が一番高いユニット数を固定した. 


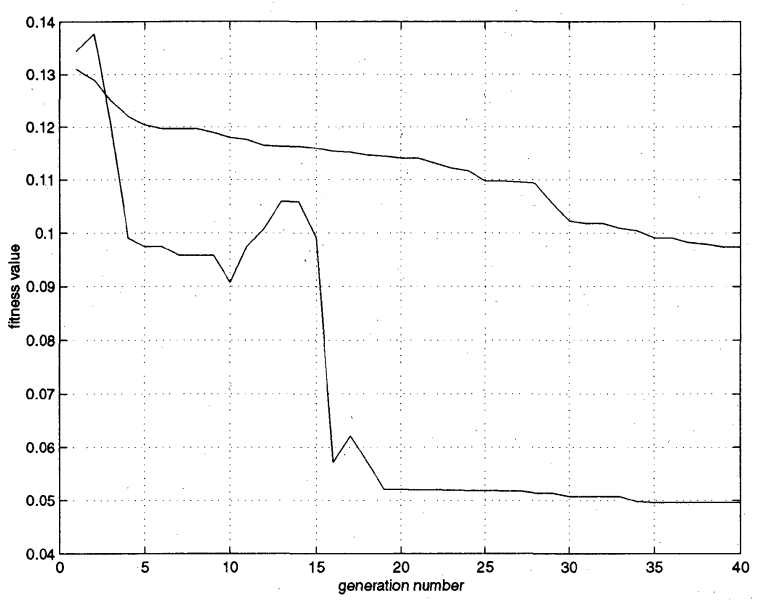

Fig. 3 The learning by using GA-SA and GA

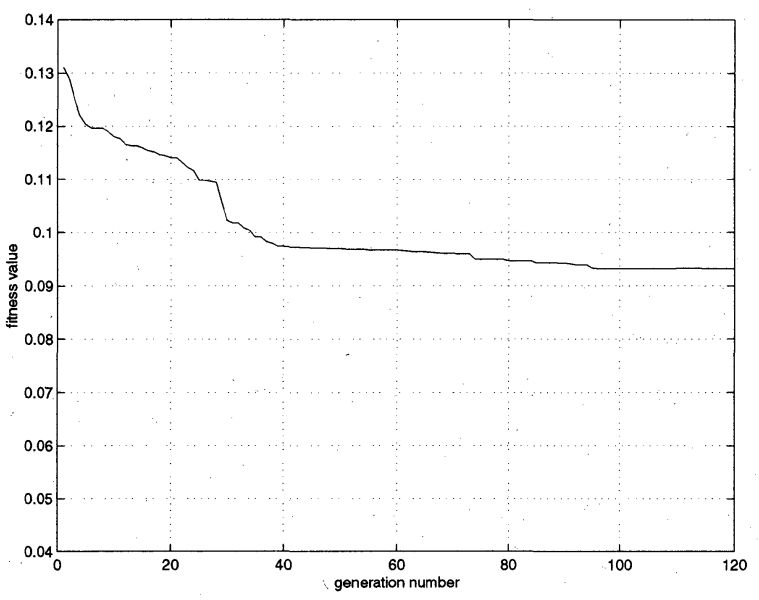

Fig. 4 The learning by using GA

た結果を Fig.4に示す.Fig.3，Fig.4から，GAと S Aを併 用したときには，40 世代において 0.05 の適応度の值を得て いるのに対して, GAのみの場合は，世代数を 120 までとっ ても, 適応度の值は 0.09 で収束していることが分った.

これらの適応度（0.13 から 0.005 ずつの変化）に対応する 認識率と入力数の関係を Fig.5 (a), Fig.5,(b) に示す.こ れらの関係から，GAのみで得られた適応度 0.09 の時と, $\mathrm{G}$ $\mathrm{A}-\mathrm{S} \mathrm{A}$ で得られた適応度 0.05 の時を比較すると, 認識率 にはあまり影響がないが，入力数の減少を確認することがで きる。

図中の青線が $\mathrm{G} \mathrm{A}$ のによる場合で，赤線が $\mathrm{GA}-\mathrm{S} \mathrm{A}$ を 用いた場合である.

このことから，GAと S Aを併用することで，局所的な 最適解をさけ，さらに，早い世代において良好な結果を得る ことが可能であった。 また，この結果から得られた N Nの入 力数は GAのみで探索を行った場合は 353 で, 初めの $32 \times$ $16(=512)$ と比べて入力数が $31 \%$ 削減されているのに対して, 本手法で得られた入力は 221 であり，入力の数が $56 \%$ 削減さ れている.さらに, 本手法では, トータルの重みの数がバイ

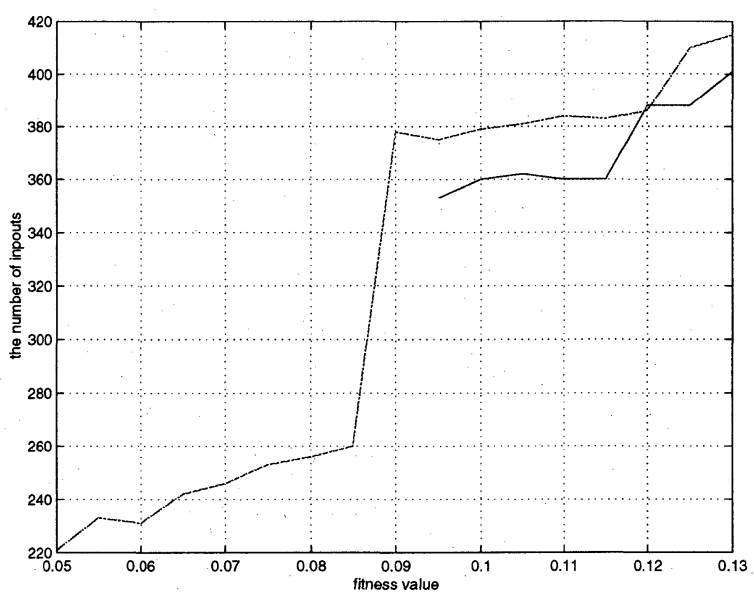

Fig. 5 (a) The relationship between the fitness value and the number of inputs

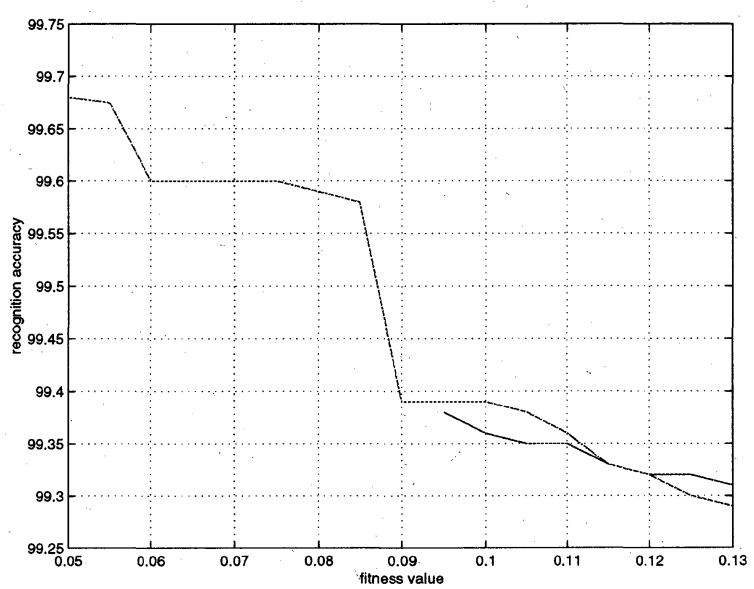

Fig. 5 (b) The relationship between the fitness value and the recognition accuracy

アス項も含めて 4524 個であり，すべての入力を用いたとき の 10344 個に比べると, 計算量を大幅に削減していることが 明らかである。: 一方，ニューロ構造を最小化する方法として 石川の提案した忘却を用いた構造学習アルゴリズム ${ }^{14) か ゙ よ く ~}$ 知られている，そこで，比較のためにこのアルゴリズムを用 いたところ,トータルの重みの数はバイアス項も含めて 7826 個であった．このことからも，本手法の有効性を検証するこ とができた．近年では，フーリエ変換後のスペクトルの対称 性を考える方法もあり ${ }^{15)}$ ，この方法に従うと入力数 288 個， トータルの重み 5864 であり，本手法の方が $23 \%$ 削減してい るが，本論文では GA と S A を併用し，入力を決定すること が目的であるため，はじめは全てのデー夕を用いて考察し， G Aと S Aを用いた場合の有効性を検証する。つまり，あら かじめ半分にしなくても，GAとSAを併用し，入力を決定 する際に，対称性を考慮した入力が得られるであろう，とい う考えからである。

GA-S Aにより得られた入力を, 横軸を円周方向, 縦軸を 半径方向とし，プロットした結果を Fig.6に示す. Fig.6に 
おいて，グレーは選ばれた入力で，黑が対称性を考えた時， 重なる部分である。このことから，Fig.6ではいくらかの入力 が（対称性を考慮すると），本来ならば選ばれなくても良い 入力であるが，GA－S Aによる探索結果を見ると残ってい る.また，GAのみで得られた入力についても同様に Fig.7 に示す. Fig.7から，GAのみで得られた NNの入力は $\mathrm{GA}$ と S A を併用したときに得られた入力にくらべ，対称性をうま く考慮できていないことが明らかになった。これにより，G Aのみでは望ましい解を得られないことが分った。 また， G Aと S A 併用したときにもいくつかが対称性が考慮されて いない部分があるが，これらを調べたところ，フーリエ変換 後の振幅スペクトルの対称性に若干の数值計算誤差が生じて いたところに原因があると考えられる（なお，この対称性で は上位 3〜4桁は一致している)。

ここで，比較のために 512 個の入力をもつ，通常の B P 法で学習させた。N Nの条件はGAと S A を併用したとき と同様，中間層のユニット数を 20 とした。ささらに，学習・ 評価を行うときの硬貨の画像枚数も同様である．このとき， 99.68\%の認識率を得ることができた。これは，320 枚の評価 用画像のうち， 1 枚の誤認識であった。しかしながら，自動 販売機など実機への適用を考えた場合，認識に要する時間は， 500 円硬貨を挿入して画像をスキャンしてから認識（真贋の 判定）を行なうまでの時間に相当する。このため，認識に要 する時間は実用上数百ミリ秒以内であることが望ましい，B $\mathrm{P}$ 法における認識時間が $T$ 秒であると仮定すると，本手法で は約 $T / 3$ 秒である. 多い演算量が高コストのプロセッサを要 求する点を考虑すると，B P 法による結果は実用的とは言え ない.

次に,フーリエ変換後の振幅スペクトルの対称性を考虑し て，あらかしめNNの入力を半分にした場合，99.06\%の認識 率を得た。これは，320枚の評価用画像のうち，3枚もの䛊 認識が生じた。また，対称性を考慮した約半分の振幅スペタ トルのデータの数值計算上の刘称性の不一致を考慮し, 残り 半分の振幅スペクトル・デー夕を用いて B P 法によるシミュ レーションを行なった。その結果，先に行なったシミュレー ションと同じ $99.06 \%$ の認識率を得た。したがって，振幅ス ペクトルの対称性の不一致は認識率を下げる直接の原因では ないと考えられる.これに対して，本手法では 512 個の入力 をもつ，通常の B P 法で学習させた時と同じく, 99.68\%の認 識率を得ることができた。しかも，演算量を考えると通常の B P 法よりも実用的である。また，すでに提案されている方 法 $^{2) \sim 5)}$ と比べ，用いた硬貨の画像が身近な（安価な）スキャ ナで取り込め，しかも，完全な画像でなくて（一部の画像で） よい点から，ハードウェア化を考慮すれば，本手法の有効性 は明らかである。

\section{5. 結 言}

本論文では，GAと S A を併用した N Nシステムの設計法 を提案した。本手法の有効性を検証するために，実際の硬貨

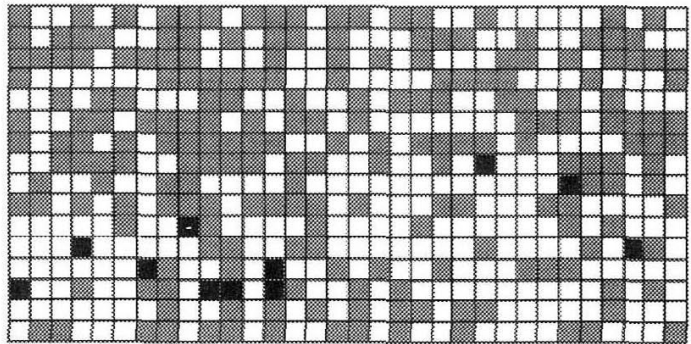

Fig. 6 The input by using GA-SA system

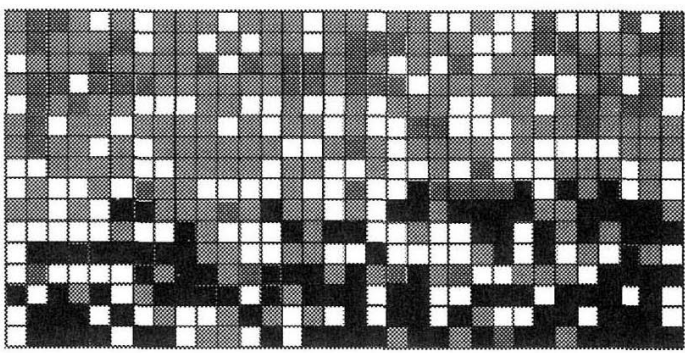

Fig. 7 The input by using GA system

の画像を用いて，500 ウォン硬貨と 500 円硬貨の識別を行う 計算機シミュレーションを行った。 その結果，GAとＳAを 併用することで，GAのみのときと比べると，比較的短時間 で望ましい解（NNの入力）を得る事ができた。このことか ら，本手法は $\mathrm{GA}-\mathrm{S} A$ $\mathrm{A} り \mathrm{NN}$ への力信号数を低減化 することができた。また，硬貨の画像が安価なスキャナで取 り込め, 硬貨全体の画像でなく，一部分だけで $100 \%$ に近 い認識率を得ることができた。このことから，計算量も少な く，低コストのシステムが実現できた。

今後は，実機への適用を考えている。

\section{参 考 文 献}

1) S.Haykin : Neural Networks, Macmillan College Publish ing Company (1994)

2) F.Takeda and S.Omatu : Rocognition System of US Dollers Using a Neural Network with Random Masks, Proc. of the International Joint Conference on Neural Networks, 2, 2033/2036 (1993)

3）竹田, 大松：ニューロ貨幣識別ボードの開発, 電気学会論文 誌，1-116-C-3, 336/340 (1996)

4）福見, 大松：遺伝的アルゴリズムによる硬貨認識用ニューラル ネットワークの設計, 電学論, 113-D-12, 1403/1409 (1993)

5）福見，大松，西川：部分的適応度を考慮した遺伝的アルゴリズ ムによるニューラルネットワークの設計, システム制御情報学 会誌, 9-2 (1996)

6) 竹田，大松，井上，尾波，小西：ニューラルネットワークを用 いた高速搬送紙幣の識別, 電学論, 112-C, 249/258 (1992)

7）寺西, 福見, 大松：ニューラルネットによるパターン認識 システム, 第 34 回システム制御情報学会講演会論文集, 105/106(1990)

8) D.E.Goldberg: Genetic Algorithm in Search , Optimization \& Machine Learning, Addison-Wesley (1992)

9）北野：遺伝的アルゴリズム，産業図書 (1993)

10) D.B.Fogel:Evolutionary Computation, IEEE press (1995)

11) K.F.Man,et al. : Genetic Algorithm for Control and Signal Processing, Springer (1997) 
12) Yen-Wei Chen, Tatsuro Enokura and Zensho Nakao : A Hybrid Approach to Blind Deconvolution Using a Genetic Algorithm and Simulated Annealing, Second International Conference on Knowledge-Based Intelligent Electronic Systems (Adelaide, Australia), 3/3, 144/149 $(1998 / 4)$

13) Foreign Coins in Toll Change Cause Mix-ups, Anger Derivers: The Daily Yomiuri (June 30,1992)

14）石川：忘却を用いたコネクショニストモデルの構造学習アル ゴリズム, 人工知能学会誌, 5-5, 595/603 (1990)

15）川又政征, 桶口龍雄 : 多次元ディジタル信号処理, 朝倉書店 (1995)

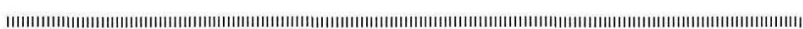

$$
\text { [著者紹介] }
$$

\section{満 倉 靖 恵（正会員）}

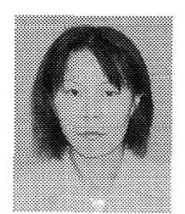

1997 年岡山県立大学大学院情報系工学研究科 修了. 同年徳島大学工学部知能情報工学科助手, 現在に至る．信号処理，生物型情報処理などの研 究に従事.

福 見

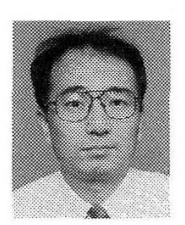

稔（正会員）

1987 年徳島大学大学院工学研究科修了. 同年同 大情報工学科助手. 95 年同知能情報工学科講師, 96 年同助教授, 現在に至る. 信号処理, 生物型情 報処理などの研究に従事. 95 年本会論文賞. 工学 博士 (京都大学).

\section{赤 松 則 男}

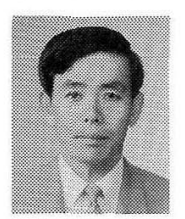

1966 年徳島大学工学部電気工学科卒業, 71 年 京大大学院博士課程了. 同年徳島大学工学部助手. 75 年同助教授. 87 年同教授. 工学博士 (京都大 学). 生体情報工学, 非線形回路, 音声の認識と 合成, 電子ペンの研究に従事. 